\title{
Michael Kay Reedy
}

\author{
Kenneth A. Taylor ${ }^{1}$ (i)
}

Received: 6 March 2021 / Accepted: 20 March 2021 / Published online: 5 April 2021

(c) The Author(s), under exclusive licence to Springer Nature Switzerland AG 2021

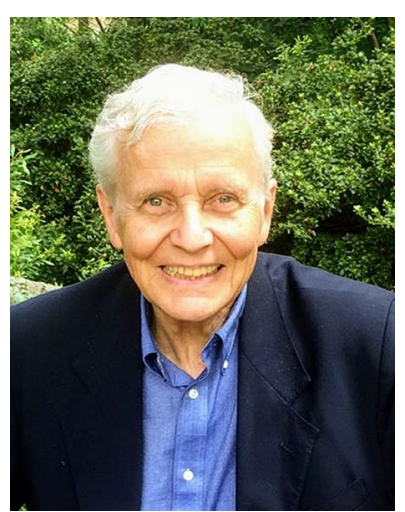

Shortly after his death, I was asked if I would write an essay about Michael Reedy's contributions to muscle research. This essay is coming embarrassingly late due to a combination of the COVID-19 pandemic, personal setbacks and my own coming to terms with the sudden and unexpected end of a long collaboration. On the principle that late is better than never, I have felt compelled to complete this request. I have been helped by several colleagues that also knew him well in particular R. J. Edwards (RJ) and Belinda Bullard who contributed several vignettes.

Dr. Michael Kay Reedy was a mainstay scientist in the structure and function of striated muscle from the middle 1960s until his retirement in 2015. He died unexpectedly on June 18, 2019, the day before his 85th birthday. Most scientists that knew Mike personally will attest to his enthusiasm for anything related to muscle and his generally engaging personality. Belinda first encountered Mike at a meeting at the Royal Society in London in 1963. She remembers a then young man striding from the back of the room talking enthusiastically about his findings on the muscle Z-disc. Who was this brave American? None other than Mike. Later,

Kenneth A. Taylor

taylor@bio.fsu.edu

1 Institute of Molecular Biophysics, Florida State University, Tallahassee, FL 32306-4380, USA when they were both at UCLA, Mike's enthusiasm for insect flight muscle drew her to follow his lead to a long career studying Lethocerus flight muscle. For all Mike's charm, his optimism, his love of friends and science, he had his crazy side. Who else would ask his British friends to carry an old microscope that he had purchased on eBay in their hand luggage from the UK, only to find when it arrived that he already had that model?

Mike was the oldest of five siblings who grew up in the Alaskan Yukon, later moving to Seattle. Mike attended the University of Washington, graduating in 1958 with a BA in Zoology. He followed his undergraduate studies at the University of Washington Medical School, where he graduated with an MD in 1962.

Mike eschewed becoming board certified and therefore never became a practicing physician. Instead, while in medical school he fell in love with the then new technique of electron microscopy (EM). This was the time period where skillfull microscopists were discovering new subcellular structures almost monthly. EM was designed for someone with Mike's temperament. Success came mostly to highly meticulous investigators. Mike's particular interest was in the beautifully ordered striated muscle. While in medical school, Mike enjoyed three NIH sponsored summer predoctoral fellowships studying muscle ultrastructure, and after his MD degree, continued with a short internship in Pathology at the University of Washington Hospital, working with Prof. H. Stanley Bennett and developing a life-long interest in the structure of the Z-disk. RJ related a story that Mike showed a colleague, presumably Prof. Bennett, some pictures of the vertebrate Z-disk which showed a square lattice. The colleague judged that they could not be correct because everyone knew that the A-band had a hexagonal arrangement of filaments. Of course, we now know that the "square" lattice is correct and accounts for the lower ratio of thin filaments to thick filaments in vertebrates. As far as I can tell, Mike never published this observation. The late Mary Reedy, his wife and collaborator of many years (d. August 8,2008 ) once commented to me that she thought Mike had reviewed every paper ever published on Z-disk structure, 
despite the fact that he did not publish on the Z-disk until RJ joined his lab as a graduate student in 1992.

In 1963 Mike began a 3-year postdoc with Hugh Huxley, at the MRC-LMB in Cambridge, England. While there and at the suggestion of the late Prof. J. W. S. Pringle, whose passion was the stretch-activated, asynchronous flight muscle physiology and structure, Mike and two life-long friends and collaborators, Ken Holmes and the late Richard Tregear (d. May 1, 2020) began studies on the giant waterbug Lethocerus sp. Mike was fascinated by the high degree of order present in this muscle, arguably the best ordered muscle in nature, and worked on it exclusively the remainder of his research career. What makes Lethocerus and all asynchronous flight muscle so well ordered is the unique arrangement of thick and thin filaments that places a thin filament between neighboring thick filaments in a location possessing diad symmetry. Though physiologically important, the arrangement permits the cutting of longitudinal sections that had alternating thick and thin filaments, which he named "myac" layers. Myac layer sections $25 \mathrm{~nm}$ thick cut parallel to the inter-thick filament axis display all the myosin cross-bridges that contacted the intervening thin filament. Thin filaments also have a helical repeat that matches the troponin-tropomyosin repeat producing the most regular arrangement of cross-bridges seen in the muscle world. No equivalent section can be cut from vertebrate skeletal muscle or any other muscle for that matter.

Mike joined the faculty in the Department of Physiology at UCLA School of Medicine in 1966 and was promoted to Associate Professor after only two years. As far as I can tell, Mike published three papers while at UCLA, all related to his postdoctoral work. In 1969, another outstanding electron microscopist, Prof. J. David Robertson, recruited Mike to join his new Anatomy Department at Duke University Medical School. Mike continued at Duke when the department was reorganized into the Department of Cell Biology with Michael Sheetz as chair and remained until his retirement.

Biological EM presents unique challenges. The ability to preserve native structure in tissue that has been chemically crosslinked (fixed), dehydrated, embedded in plastic, sectioned in orientations that favorably reveal the underlying structure and then stained sufficiently to bring out that structure were and remain skills that few have mastered. As a postdoc, Mike honed this skill which resulted in a seminal paper with Ken and Richard published in 1965 in Nature that revealed two completely different conformations of the myosin heads, one in rigor muscle angled at $\sim 45^{\circ}$ and another at $90^{\circ}$ following ATP addition at low $\left[\mathrm{Ca}^{2+}\right]$, which produced a state similar to relaxed muscle. This difference suggested that myosin heads attached to the thin filament at a near perpendicular angle when nucleotide bound and then rotated to $45^{\circ}$ to generate force and filament movement when the cleaved nucleotide is released. This was a key experimental finding incorporated into Hugh Huxley's 1969 swinging cross-bridge model, which dominated the muscle field until replaced in 1993 by the swinging lever arm model after Ivan Rayment solved the myosin crystal structure. This work would earn Mike the 1966 Newcomb S. Cleveland Prize from the AAAS and cemented his reputation in the muscle field.

Mike's work on Lethocerus flight muscle created some memorable terminology. "Crowns" describe the arrangement of myosin heads at each $14.5 \mathrm{~nm}$ repeat along the relaxed thick filament; "target zones" described the restricted region along thin filaments where strong binding (rigor) myosin heads bind; "double chevrons" describe the arrangement of rigor myosin heads in flight muscle; "lead bridges" are one of the paired double chevrons; "rear bridges" are the other; "flared Xs" are the unique myosin head arrangement seen in $15 \mathrm{~nm}$ cross sections of rigor flight muscle; "troponin bridges" are the myosin head attachments to the troponin complex of Lethocerus flight muscle; the previously mentioned "myac layers"; actin layers are sections of similar thickness containing only thin filaments.

In the academic year 1978-1979 Mike and Mary Reedy spent a sabbatical at the EMBL funded by a fellowship from the Alexander von Humboldt Foundation. Among the many studies done while there, they used EM and synchrotron $\mathrm{X}$-ray diffraction to investigate the effects of the non-hydrolyzable ATP analog AMPPNP on flight muscle structure with Roger Goody, Waltraud Hoffman and Gerd Rosenbaum. At this same time, in collaboration with Kevin Leonard he established the number of myosin molecules per unit length in isolated Lethocerus thick filaments, which concluded that there are 4 myosin molecules per crown and that the thick filaments are four-stranded, an observation important at the time when multiple symmetries were being proposed. The AMPPNP work also provided a platform for assessing the effect of various steps in the fixation procedures using X-ray fiber diffraction. As an old school electron microscopist, Mike was keenly aware of the possibility that the many steps used to prepare muscle for thin sectioning could introduce artefacts. It was after this, Mike settled on a fixation procedure unique to Lethocerus flight muscle, dubbed TAURAC for tannic acid-uranyl acetate. TAURAC avoided the two main problem reagents for actin fixation, osmium tetraoxide and glutaraldehyde. Importantly, he later showed it worked for quick frozen, freeze substituted muscle tissue.

I first met Michael and Mary Reedy at a Muscle meeting in 1979 held in Alpbach, Austria. They were at the end of their sabbatical at the EMBL. This was my first time at this particular muscle meeting. I had accepted a faculty position the Duke Anatomy Department, but was still living in England and would not be returning to the US for about a year. They were interested in imaging their Lethocerus 
flight muscle thin sections in 3D and after moving to Duke we began a collaboration that lasted 39 years in which they did all the "wet" experimental work and my lab did the 3-D imaging.

One of the more vivid memories I have is of the first paper we wrote together reporting our first 3-D reconstruction on rigor flight muscle published in 1984 in Nature. At the time I was also collaborating with the late Prof. Anthony Martonosi on the structure of the sarcoplasmic reticulum calcium ATPase. Anthony, a prolific writer, had the practice of reading aloud everything that he wrote, a practice I found very useful as a way of identifying poor composition. I adopted this practice at Duke and Mike, Mary and I sequestered ourselves in my $10 \times 10$ foot office in the Sands Building and worked away, reading every sentence aloud however many times it took to make it perfect in our view.

I learned a few things from this experience. First, Mike and Mary had their own separate ideas on what their data, as well as the published literature, meant. These ideas did not always intersect. Second, Mary could hold her own in an argument. She knew the flight muscle literature as well or better than just about anyone and could not be easily persuaded from an opinion she held strongly; you had to prove her to be wrong. Third, my office was not nearly as sound proof as I thought. For weeks after, passers by would peer in curious as to the source of all the commotion.

In the 1980s an active muscle research area was the effect on muscle of non-hydrolyzable ATP analogs for the possible trapping of muscle cross-bridges in stages of their powerstroke. One of these, AMPPNP, sometimes in combination with ethylene glycol, was a favorite for insect flight muscle. Working with Roger Goody and Richard Tregear who did the muscle mechanics and Mary who did the electron microscopy, they attacked the question of whether AMPPNP produced some unique actin-attached myosin head conformations. With Evan Eisenberg's group at the NIH, Mike showed that AMPPNP had $8 \times$ higher affinity for Lethocerus myosin heads than it had for rabbit muscle myosin. Consequently, the actin-attached forms produced by AMPPNP, although unexpected, had some significance, even if not completely understood. AMPPNP alone showed rigor-like lead bridges in myac-layer sections; in combination with ethylene glycol and low temperature, myac layers looked more relaxed but the mechanics showed high stiffness indicating actin attachment. At a time where Hugh Huxley's rowing cross-bridge model of muscle contraction was dominant, the work by Mike and his coworkers concluded that rather than the entire cross-bridge changing angle as tension is generated, domains of the myosin head changed position as tension was generated. Much of this is now understandable from the myosin head crystal structures and the relaxed thick filament structure. Mike's work discovered actin attached myosin head structures previously not visualized, such as the "unflared-X", a version of the rigor flared X but with azimuthally straight myosin heads rather than the severely bent forms seen in rigor and the "mask motif", a myosin head arrangement that suggested target zones could be relayed from one crown to another. The latter were also found in 3-D images of fast frozen, actively contracting flight muscle.

Stretch activation is one of the defining characteristics of asynchronous flight muscle. However, Lethocerus muscle was also capable of isometric contractions when $\left[\mathrm{Ca}^{2+}\right]$ was at maximum, a property contradictory to its stretch activation behavior. Mike advocated that Lethocerus used isometric contraction to warm up their muscles to the $40{ }^{\circ} \mathrm{C}$ where myosin's ATPase activity was a better match for the wing beat frequency. Exactly when I don't know, but before I left Duke in 1995, Mike purchased a video camera that he used to record literally everything such as his smash freezing experiments. Mike had the idea that if he let the bugs warm up their flight muscles and fly around a bit, their muscles would be better ordered. What better place to test this idea out than Dave Robertson's former office! Anyway, Mike and Carmen Lucaveche, his technician, now deceased, let some bugs fly around while Mike filmed them. Mike's narration is quite funny. It shows all the enthusiasm that he put into every experiment he ever did. Although entertaining, the video illustrates an important point that Mike always emphasized; the bugs had to perform isometric exercises to warm up their flight muscles before they could fly.

How Lethocerus switched from isometric to stretch activated contractions remained a mystery that Mike investigated in one of his numerous visits to Vincenzo Lombardi's laboratory. This effort, published in 2004 in the Biophysical Journal, showed that stretch activated contractions are complementary to $\mathrm{Ca}$-activated isometric contractions because both recruit from a limited pool of cross-bridges. Hence the rising plateau of isometric tension with rising $\left[\mathrm{Ca}^{2+}\right]$ progressively reduces the amount of myosin available for stretch activation. When the maximum isometric tension plateau at $\mathrm{pCa} \sim 4.5$ is reached, little or no myosin remains to be recruited for additional stretch activated tension.

Mike was both affable and enthusiastic, the latter was his special gift as a scientist making him well suited to assemble and motivate diverse teams of scientists from around the world. Mike, like several other muscle electron microscopists, was inspired by the 1985 Nature paper by Tsukita and Yano on the rapid freezing and freeze substitution of unfixed muscle tissue, a result that opened the possibility of trapping muscle in different stages of contraction. Again, Mike's choice of model system proved advantageous. Yale Goldman, another long-time collaborator of Mike's, was at that time smash freezing vertebrate striated muscle at different stages of contraction using an apparatus that he and Clara Franzini-Armstrong had developed at the University 
of Pennsylvania. Mike and Mary would travel to Philadelphia periodically to smash freeze Lethocerus muscle and return to Duke to do the microscopy. My lab would do the 3-D imaging. Subtomogram averaging and classification were in their infancy at the time, but we were able to apply the technique for the first time to actively contracting flight muscle frozen by impact on a liquid helium cooled copper block all the time monitoring tension. That work culminated in three papers by Shenping Wu, Hanspeter Winkler and others that showed how to identify and quantify numerous attached states of myosin, both strong, tension generating and weak, and applied it to isometric contraction and following a rapid stretch or release. Numerous weak myosin head attachments to actin were also found, some attaching to troponin, which might prove important for the phenomenon of stretch activation.

Mary Reedy's passing in 2008 brought an end to the EM and 3-D imaging of thin flight muscle sections. Her ability to identify excellent, as distinct from just ordinary or even poor preservation in the highly useful myac layers could not be replaced. Our lab tried reconstructing data collected from thicker sections that if successful would have provided a vehicle for eliminating the missing wedge in subtomogram averages but without success; well preserved cross-bridges could not be identified in a thick section. Mike and his former graduate student R. J. Edwards, who rejoined Mike's lab in 2007, then moved on to study the X-ray diagram of Lethocerus muscle in various states and my lab moved on to study its thick filament structure.

Mike was always fascinated by the X-ray fiber diffraction of Lethocerus muscle starting from his postdoctoral work. Lethocerus flight muscle produces perhaps the most detailed fiber diffraction of any muscle. His earlier collaborations with Richard Tregear established that during active contractions, myosin heads bound to target zones midway between troponin complexes along the thin filament. This observation was further strengthened by the electron tomography of smash frozen isometrically contracting muscle mentioned above. Coincidentally at this time, the speed of X-ray detectors was increasing to the point that changes in the entire low angle pattern could be visualized with millisecond time resolution. These studies were able to demonstrate that myosin heads attach to the troponin complex during cycles of stretch activated contractions.

Mike supervised and mentored three doctoral students during his career at Duke. The first was a MD-PhD student, Dr. William Garrett (d. 5/4/2019) who became a long-time faculty member in the Department of Orthopedic Surgery at Duke University Medical Center. Together they supervised Dr. Douglas Law (d. 3/27/2013) in his investigations into the myotendinous junction. Dr. Law later joined the faculty in the School of Biological Sciences at the University of Missouri Kansas City. Dr. Robert J. Edwards, Mike's student from 1992 to 1998, was as passionate about Z-disks as Mike and studied its conformational changes as his $\mathrm{PhD}$ research thereby bringing Mike back into the topic of Z-disk structure and function. RJ later rejoined Mike's lab as Mike's lab manager in 2007 and stayed past Mike's retirement in 2016 until the end of their NIH grant. He is currently a faculty member at Duke University's Human Vaccine Institute.

Mike had a unique style of writing, which can be seen in those papers for which he is the sole author. He also had a unique style for critiquing manuscripts and grants. If your paper or grant was reviewed by him, you knew it. He did not need to sign it. No other style was like his. I don't think this ever caused him problems because even his negative feedback was given in a positive way. There was nothing about Mike to dislike.

Mike always had a vision of what was needed to move the project forward, what would work, and put together the collaborators and skills to make it happen. The fast freezing of active muscle was a case in point. The ultimate imaging of active muscle in 3-D would never have happened had Mike not put his energy into mastering the freezing and freeze substitution of the tissue. That particular work remains to this day, unique in the field. No other muscle specimen has been imaged in 3-D after being frozen during active contraction to produce molecular details of how muscle works. Mike's work with X-ray fiber diffraction of water bug flight muscle still shows the most detailed patterns of any muscle, much of it still not understood.

Mike's first stroke in July 2013 marked the end of his being able to contribute to any writing. Although he appeared to make a full recovery, his ability to process written information was reduced. He visited Tallahassee later that year after celebrating Thanksgiving with Mary Reedy's brother in Ft. Walton Beach, FL, saw what was going on in the lab, contributed what he could and generally filled the lab with his energy. His stroke did not diminish his enthusiasm for muscle studies.

Mike also had a great sense of adventure. One adventure was reestablishment of the lab's source of water bugs which was becoming dangerously low. I had introduced him to Dr. Puey Ounjai, a structural biologists from Thailand at the 2014 San Francisco Biophysical Society meeting. I thought Dr. Ounjai might be able to make a connection in Thailand for obtaining live Lethocerus. Mike pursued the idea, made the arrangements, traveled to Southeast Asia in February, 2015 and stayed for two weeks collecting water bugs. He made a second trip in May 2015, staying for 10 days. Undertaken after his first stroke made both trips doubly adventurous. Reading Mike's E-mails about this trip even today is a pleasant process as they are a perfect reflection of the man. Mike was a real detail person who tried to anticipate all the problems that might crop up, one of which was to secure 
a "holding tub" that could maintain his ever-growing collection of live water bugs. I wonder what the house maid thought? Everyone received as many pictures as Mike could assemble in a sequence of E-mail attachments. Although this might seem minor in the grand scheme of things, the high resolution structure of the Lethocerus thick filament would not have happened had he not made these trips.

Two other outcomes of Mike's trips to Thailand are worth noting. In 2015, a project to sequence the Lethocerus genome was stalled due to lack of genomic DNA. Feng Qiu and colleagues in Shanghai, were doing the sequencing, but importing Lethocerus muscle into China proved to be difficult. On his second trip to Thailand, Mike collected more bugs, dissected flight muscle and prepared the muscle for extraction of RNA and DNA in a lab in Bangkok. He then flew to Hong Kong airport, with the samples in a paper coffee cup carried his pocket; there he met Feng Qiu and handed over the samples. Without this sterling effort, the Shanghai contribution to the sequencing would have been impossible. Mike was overjoyed when, in February 2019, the sequence was completed, and mostly annotated. He suggested a grand party to celebrate. In 2016, a consignment of Lethocerus from Mike's contact in Bangkok arrived in the Bullard lab in York, UK. While in York, Mike sat in a small office dissecting flight and leg muscle from the bugs and processed them for later RNA extraction. This was used by RJ Edwards and Lanette Fee in the sequencing of Lethocerus myosin at Duke.

Unconventionally transporting samples is a common theme with Mike. When RJ was a grad student and together went to the synchrotron at Daresbury, Mike carried the glycerinated muscles in an ordinary thermos filled with dry ice, loosely capped, in his carry-on bag. Those were different times.

At the last three Biophysical Society Meetings, Mike and I shared a hotel room. Mike was fun to share a room with. You quite literally did not know what to expect. Mike, Mary and I started a tradition of the Duke insect flight muscle group, which was literally the two of them, myself, Dianne if she attended, and any postdocs or students I had that were attending. We carried this on even after I left Duke in 1995. At the 2018 San Francisco meeting, my Persian graduate students picked out a Persian restaurant in San Francisco where Mike and I treated them to a cultural dinner, which they arranged. Facilitated largely by Mike's friend, Nancy Porter, Mike attended the 2019 Biophysics meeting, which was held in Baltimore, Mike spent most of his time reconnecting with his old friends and collaborators, none of whom could have anticipated that it was the last time they would see each other. At the time, I was finishing up a review article that I had decided would cover all the work that Mike, Mary and I had done together. It would prove to be the last thing we would write together. I had desperately wanted Mike's opinion on the final product, but at that point, he continued having difficulty processing written information. However, he was still sharp in conversation and his encyclopedic memory remained intact. So in our spare time I read the manuscript aloud to him, in a way coming full circle.

My students and postdocs loved Mike and really enjoyed being around him and especially his enthusiasm about what they were doing. I miss his advice not just on the science we shared, but his opinions on the science that had been done. He would never judge a paper to be complete rubbish; I think the worst thing he would say was that a publication might have needed some more work to establish the point. I loved him like a father. He looked after me during the early part of my academic career. The first time my grant money ran out, which would have been fatal for someone in my position at Duke, he, Jane Richardson and others who are unknown to me, put together funding to keep me going till I could get my grant renewed. I cherish the memories of the times I traveled up to Duke to stay with Mike and Mary to work on manuscripts or to discuss upcoming grant applications. Continuing work on this exotic bug to which he introduced me and others and enthusiastically promoted, continues to produce remarkable results of importance to understanding muscle structure and function.

Publisher's Note Springer Nature remains neutral with regard to jurisdictional claims in published maps and institutional affiliations. 